Research Paper

\title{
Recovery effect of pre-germinated brown rice on the changes of sperm quality, testicular structure and androgen receptor expression in a rat model of drug addiction
}

\author{
Samur Thanoi ${ }^{1,2}{ }^{\varpi}$, Jureepon Roboon ${ }^{1}$ and Sutisa Nudmamud-Thanoi ${ }^{1,2}$ \\ 1. Department of Anatomy, Faculty of Medical Science, Naresuan University, Phitsanulok, Thailand \\ 2. Centre of Excellence in Medical Biotechnology, Faculty of Medical Science, Naresuan University, Phitsanulok, Thailand \\ $\triangle$ Corresponding author: Samur Thanoi, PhD., Department of Anatomy, Faculty of Medical Science \& Centre of Excellence in Medical Biotechnology, Faculty of \\ Medical Science, Naresuan University, Phitsanulok 65000, Thailand. Tel: +66 55 964600; Fax: +66 55 964770; E-mail: samurt@nu.ac.th \\ (C) Ivyspring International Publisher. This is an open access article distributed under the terms of the Creative Commons Attribution (CC BY-NC) license \\ (https://creativecommons.org/licenses/by-nc/4.0/). See http://ivyspring.com/terms for full terms and conditions.
}

Received: 2018.03.15; Accepted: 2018.05.27; Published: 2018.06.12

\begin{abstract}
Drug addiction is reported to have adverse effects in male reproduction. Dextromethorphan (DXM) administration was used in this study as a model of addiction in rats, and various treatments including the use of pre-germinated brown rice (PGBR) were investigated for their effects on the changes of sperm quality, testicular structure and androgen receptor (AR) expressions in rats receiving DXM. The results demonstrated that these animals showed significant reduction in all parameters of sperm quality, an increase in abnormal testicular structure and decreased androgen receptor expression in spermatogenic, Sertoli and Leydig cells. However, different effects of the treatments applied in this study were observed with the greatest recovery effect from treatment with PGBR. Sperm motility and sperm concentration reverted to normal after treatment with PGBR for 60 days. Moreover, all parameters of testicular structure also returned to normal after 60 days of PGBR treatment, as well as AR expression in Sertoli and Leydig cells. Therefore, we have demonstrated that PGBR treatment can reverse the changes in sperm quality, testicular structure and $A R$ expression in addicted animals and PGBR may be a novel therapeutic strategy for the treatment of drug addiction.
\end{abstract}

Key words: Drug addiction, Dextromethorphan, Sperm quality, Testicular structure, Androgen receptor

\section{Introduction}

Drug addiction is reported to have adverse effects on the male reproductive system including disruption of the reproductive axis [1], reduced testosterone $[2,3]$ and decreased sperm quality $[4,5,6,7]$. Furthermore, apoptosis of germ cells $[6,7]$ and decreased testosterone level [8] can be induced by methamphetamine.

Dextromethorphan (DXM) is an antitussive or cough suppressant drug. At high dosages, DXM can act as a dissociative hallucinogen via multiple effects, including as a nonselective serotonin reuptake inhibitor [9]. Within the past few years illicit use and drug abuse of antitussive drugs, especially DXM, have risen. Therefore, DXM was used in this study as a model of drug addiction in rat.

We previously demonstrated that pre-germinated brown rice (PGBR) has a recovery effect on improving sperm quality in a rat model of depression [10]. PGBR is a food supplement which contains many effective substances including $\gamma$-oryzanol, a-tocopherol (vitamin E), pyridoxine (vitamin B6), thiamine (vitamin B1) and high GABA [10]. Therefore, we investigated whether PGBR would be an effective treatment in this study in comparison with other treatments including drug withdrawal, Diazepam (a 
common drug treatment for addiction), and standard GABA (gamma-aminobutyric acid). The results from this study will provide scientific information for the potential use of a natural product as an alternative treatment in improving testicular and sperm damages caused by drug addiction.

\section{Methods}

\section{Animals}

Male Sprague-Dawley rats aging 5 weeks and weighing between 200-250 g from National Animal Center, Salaya, Nakorn Pathom, Thailand were used in this study. The animals were housed at $24 \pm 1{ }^{\circ} \mathrm{C}$ under dark-light cycle 12:12 hours at Center for Animal Research of Naresuan University. All animals were treated according to the guidelines for animal care and use of laboratory animals, and the protocols were approved by the Animals Research Committee of Naresuan University, Thailand.

\section{Drug and reagent administrations}

The drug and reagents used in this study were described below;

- Dextromethorphan (DXM); dextromethorphan hydrobromide was purchased from SigmaAldrich ${ }^{\circledR}$ Lot\#090M1298V.

- Diazepam was obtained from Naresuan University Hospital.

- Gamma aminobutyric acid; GABA was purchased from Sigma Chemical Company, St. Louis, USA. Amount of synthetic GABA was equaled with the GABA found in PGBR. GABA was dissolved in distilled water before used.

- Pre-germinated brown rice (PGBR) was supplied by the Laboratory of Faculty of Agriculture Natural Resources and Environment, Naresuan University. Briefly, Brown rice (Oryza sativa var. glutinosa) from KhekNoi, KhaoKho, Phetchabun (Thailand) was soaked for 24 hours until germinated. PGBR was dried, ground to a powder and suspended in distilled water before use.

\section{Experimental design}

The animals were divided into 6 groups with 7 animals each and treated as described below (Figure 1);

- Control group (Control): Animals were treated with normal saline by oral administration via gavage for 75 days.

- Dextromethorphan group (DXM): Animals were treated with $30 \mathrm{mg} / \mathrm{kg}$ DXM via intraperitoneal injection (i.p.) for 15 days and sacrificed on the last day of treatment.
- Dextromethorphan and drug withdrawal 60 days group (DW60): Animals were treated with $30 \mathrm{mg} / \mathrm{kg}$ DXM for 15 days (i.p.) and withdrawn for 60 days, respectively.

- Dextromethorphan and diazepam 15 days group (DD60): Animals were treated with $30 \mathrm{mg} / \mathrm{kg}$ DXM for 15 days (i.p.) and treated with $10 \mathrm{mg} /$ $\mathrm{kg}$ diazepam for 60 days by oral administration via gavage, respectively.

- Dextromethorphan and synthetic GABA 60 days group (DG60): Animals were treated with 30 $\mathrm{mg} / \mathrm{kg}$ DXM for 15 days (i.p.) and treated with $0.8 \mathrm{mg} / \mathrm{kg}$ synthetic GABA for 60 days by oral administration via gavage, respectively.

- Dextromethorphan and PGBR 15 days group (DP60): Animals were treated with $30 \mathrm{mg} / \mathrm{kg}$ DXM for 15 days (i.p.) and treated with $5 \mathrm{~g} / \mathrm{kg}$ PGBR for 60 days by oral administration via gavage, respectively.

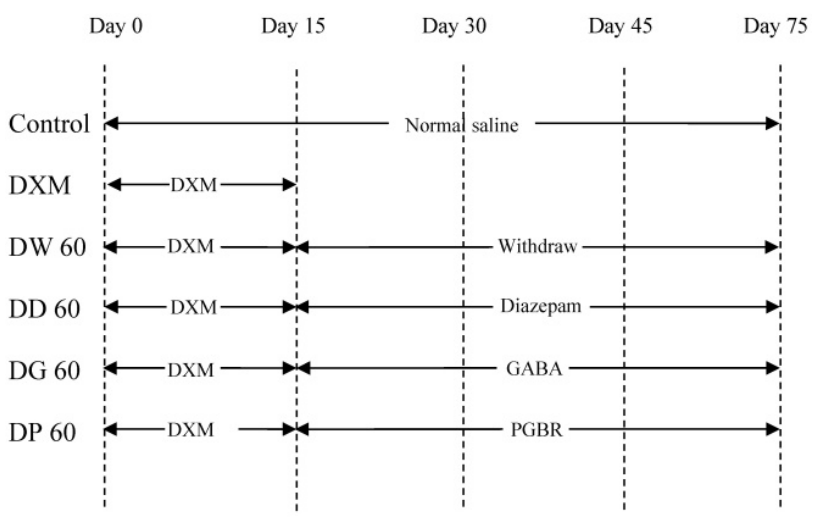

Fig. 1. The schematic diagram of experiment in rat model of addiction

\section{Sample collection and Tissue preparation}

After treatments, all animals were sacrificed by cervical dislocation. The testes and epididymis were immediately dissected and weighed. Sperm were released from cauda epididymis in phosphatebuffered saline (PBS) at $37^{\circ} \mathrm{C}$ and assessed for the percentage of sperm motility. The remaining samples were maintained and fixed in $10 \%$ formaldehyde for evaluating sperm morphology and concentration.

Each testis was cut, placed in cassettes and washed in PBS 3 times for 5 minutes. Then, the tissues were processed for routine paraffin embedding until sectioning. The tissue blocks were sectioned at $5 \mu \mathrm{m}$ thickness and sections were floated on warm water $(45 \circ \mathrm{C})$ in a water bath before mounting onto the microscope slides coated with 3-(Triethoxysilyl)propylamine (S6225919 110; Merck, Hohenbrunn, Germany). The sections were allowed to dry overnight at room temperature before evaluating testicular structure and androgen receptor expression. 


\section{Sperm quality analysis}

Sperm quality parameters including sperm motility, sperm morphology and sperm concentration were assessed. The protocols for each parameter followed the protocol described by Roboon et al. (2017) [10] briefly.

\section{Sperm motility}

Spermatozoa were assessed for the percentage of sperm motility using a Makler counting chamber and counted under bright field (40X objective lens). The motile and non-motile sperm were evaluated and calculated.

\section{Sperm morphology}

Spermatozoa were stained and assessed for the percentage of normal sperm morphology with a total count of 200 spermatozoa in each group.

\section{Sperm concentration}

Sperm concentrations were assessed using a hemocytometer and counting under bright field (40X). The results of sperm concentration were reported in term of epididymal sperm number $\left(10^{6} \mathrm{cells}\right) / \mathrm{ml}$.

\section{Testicular and epididymal structure analysis}

\section{Testicular and epididymal weight}

Before being sacrificed, rats were weighed to obtain body weight. After that, the testes and epididymes were immediately dissected and weighed. The data were evaluated and calculated as a testicular/epididymal weight per body weight.

\section{Morphological changes of seminiferous tubules}

Morphological changes of seminiferous tubules were analyzed followed the protocols described by Roboon et al. (2017) [10]. Briefly, two sections per animal were used. Each hematoxylin-eosin stained section was evaluated under a light microscope (Nikon eclipse 08i; Nikon, Bangkok, Thailand, Co., Ltd.) and a picture taken using a computerised image capture system (Nikon digital camera DXM1200c, Nikon, Bangkok, Thailand, Co., Ltd.). The data were shown as percentage of each morphological type of in seminiferous tubule per total number of seminiferous tubules in each section.

\section{Immunohistochemistry analysis (Expression of androgen receptor)}

Androgen receptor (AR) expression was detected in rat testis by using the indirect immunohistochemistry technique. Briefly, testicular sections were deparaffinized and rehydrated. After that, the antigen was retrieved with high temperature heating at $70 \mathrm{P}$ or 560 Watt in microwave for 5 minutes, 3 times. Then, the sections were incubated with endogenous peroxidase blocking solution $(10 \%$ methanol, $0.3 \% \mathrm{H}_{2} \mathrm{O}_{2}, 1 \%$ triton-X and PBS) for 30 minutes and washed with PBS 3 times for 5 minutes each. The sections were incubated with non-specific protein blocking solution ( $5 \%$ normal goat serum and PBS) for 2 hours. After that, the sections were incubated with AR primary antibody (Rabbit polyclonal IgG, Santa Cruz Biotechnology, USA and Merck Millipore, US) at a dilution of 1:25 in PBS containing 5\% normal goat serum for 4 hours. The sections were then washed with PBS 3 times and incubated with biotinylated secondary antibody for 2 hours and washed with PBS 3 times. Then the sections were incubated with avidin-biotinylated horseradish peroxidase complex (ABC kit) (Vector Laboratories, Burlingame, California, USA) for 60 minutes and the sections were washed with PBS 3 times for 5 minutes each. The specific proteins were visualized with chromogen 3,3'-Diaminobenzidine (DAB) (Vector Laboratories, Burlingame, California, USA) for 6 minutes and rinsed in distilled water for 5 minutes. The sections were dehydrated in a series of increasing alcohol concentrations, and alcohol removed with xylene. Finally, the tissues were mounted with mounting media (Fisher scientific, New Jersey, USA).

Each immunostained section was evaluated under a light microscope at magnification 20X using the computerized image capture system. Two sections per animal were used and 10 seminiferous tubules were randomly selected from each section. AR immunopositive cells were analyzed by ImageJ software (http://rsb.info.nih.gov/ij/). The data were presented as percentage of positive cells per total cell number.

\section{Statistical analysis}

Data were analyzed by one-way analysis of variance (ANOVA). The statistical significances were determined as $p<0.05$. The results were expressed as mean \pm SEM.

\section{Results}

\section{Sperm quality}

\section{Sperm motility}

Rat sperm motility in the DXM group was dramatically decreased $(p<0.001)$ when compared to the control group. Animal receiving DXM for 15 days and treated with diazepam and GABA standard for 60 days showed a recovery in the percentages of sperm motility but these were still significantly lower than the control. Animals receiving DXM for 15 days and withdrawn from this drug for 60 days and animals treated with PGBR for 60 days showed percentages of 
recovery in sperm motility close to control values, most notably in animals treated with PGBR (Table 1).

\section{Sperm morphology}

The percentage of normal sperm morphology in animals treated with DXM alone also showed a highly significant difference $(\mathrm{p}<0.001)$ when compared to the control group. The percentages of normal sperm morphology in animals in all treated groups gradually recovered when compared with animals treated with DXM alone but still showed significant differences when compared with the control. However, animals treated with PGBR showed the most recovery in the percentage of normal sperm morphology (Table 1).

\section{Sperm concentration}

Animal treated with DXM alone showed a highly significant deficit in sperm concentration $(p<0.001)$ when compared with controls. Animals in the groups of DXM with drug withdrawal for 60 days, and DXM with diazepam for 60 days also showed significant differences from controls. However, animals treated with GABA standard and PGBR showed no significant differences from the control group (Table 1).

\section{Testicular structure}

Testicular and epididymal weight

Only in animals treated with DXM showed significant changes in the testicular and epididymal weight when compared with the control group. There was a significant increase in the percentage of testicular weight/body weight $(p<0.001)$, while the percentage of epididymal weight/body weight was decreased (Table 2).

\section{Morphological changes of seminiferous tubules}

All parameters of morphological changes in seminiferous tubules showed significant increases in animals treated with DXM alone. Additionally, vacuolization and irregular tubules were also significantly increased in animals treated with diazepam. Apart from that, other treated groups showed a recovery effect of treatment reflected by no significant differences when compared with controls (Table 2).

\section{Expression of androgen receptor (AR)}

The percentages of AR expression in all cell types measured in animals receiving DXM alone was significant lower when compared to the control. Similarly, significant decreases in AR expression in all cell types were also found in animals following drug withdrawal for 60 days and in animals treated with diazepam. Animals treated with GABA standard and PGBR showed a recovery effect in some cell types; Leydig, Sertoli and peritubular myoid cells were not significantly changed when compared to controls, but spermatogonia, round spermatid and elongated spermatid were still significantly affected (Table 3 ).

Table 1. Sperm quality parameters measured in the control, Dextromethorphan only and treatment groups: Control, Dextromethorphan only (DXM), Dextromethorphan+Drug withdrawal (DW60), Dextromethorphan+Diazepam (DD60), Dextromethorphan+GABA standard (DG60) and Dextromethorphan+Pre-germinated brown rice (DP60)

\begin{tabular}{|c|c|c|c|c|c|c|}
\hline Parameter & Control & DXM & DW60 & DD60 & DG60 & DP60 \\
\hline Sperm Motility (\%) & $65.07 \pm 3.37$ & $2.86 \pm 2.86^{* * *}$ & $56.94 \pm 0.01$ & $48.35 \pm 2.52^{* *}$ & $54.40 \pm 2.65^{*}$ & $60.74 \pm 2.51$ \\
\hline Normal Sperm Morphology (\%) & $92.79 \pm 0.69$ & $6.00 \pm 2.35^{* * *}$ & $87.64 \pm 1.07^{* * *}$ & $84.36 \pm 0.83^{* * *}$ & $86.14 \pm 0.88^{* * *}$ & $89.50 \pm 0.80^{*}$ \\
\hline $\begin{array}{l}\text { Sperm Concentration } \\
\left(\times 10^{6} / \mathrm{ml}\right)\end{array}$ & $260.06 \pm 8.05$ & $18.19 \pm 3.01^{* * *}$ & $215.68 \pm 7.87^{\star * *}$ & $215.74 \pm 5.70^{* * *}$ & $252.30 \pm 3.84$ & $254.54 \pm 3.05$ \\
\hline
\end{tabular}

Table 2. Testicular and epididymal weight and morphological changes of seminiferous tubules in the control, Dextromethorphan only and treatment groups: Control, Dextromethorphan only (DXM), Dextromethorphan+Drug withdrawal (DW60), Dextromethorphan + Diazepam (DD60), Dextromethorphan + GABA standard (DG60) and Dextromethorphan+Pre-germinated brown rice (DP60)

\begin{tabular}{|c|c|c|c|c|c|c|}
\hline Parameter & Control & DXM & DW60 & DD60 & DG60 & DP60 \\
\hline $\begin{array}{l}\text { Testicular weight/Body } \\
\text { weight }\end{array}$ & $0.47 \pm 0.01$ & $0.59 \pm 0.01^{* * *}$ & $0.45 \pm 0.01$ & $0.48 \pm 0.01$ & $0.46 \pm 0.02$ & $0.43 \pm 0.01$ \\
\hline $\begin{array}{l}\text { Epididymal } \\
\text { weight/Body weight }\end{array}$ & $0.14 \pm 0.01$ & $0.09 \pm 0.01^{* * *}$ & $0.14 \pm 0.01$ & $0.15 \pm 0.01$ & $0.15 \pm 0.01$ & $0.14 \pm 0.01$ \\
\hline $\begin{array}{l}\text { Separation of germinal } \\
\text { epithelium }(\%)\end{array}$ & $11.61 \pm 0.67$ & $22.60 \pm 1.25^{\star * *}$ & $13.31 \pm 0.98$ & $14.54 \pm 1.73$ & $12.48 \pm 0.86$ & $12.16 \pm 0.76$ \\
\hline Vacuolization (\%) & $3.16 \pm 0.14$ & $5.16 \pm 0.32^{* * *}$ & $3.32 \pm 0.28$ & $3.93 \pm 0.15^{* *}$ & $3.19 \pm 0.09$ & $3.07 \pm 0.11$ \\
\hline $\begin{array}{l}\text { Luminal sloughing of } \\
\text { germ cells }(\%)\end{array}$ & $0.51 \pm 0.04$ & $1.31 \pm 0.18^{* *}$ & $0.50 \pm 0.06$ & $0.60 \pm 0.10$ & $0.50 \pm 0.05$ & $0.51 \pm 0.06$ \\
\hline $\begin{array}{l}\text { Irregular tubule } \\
(\%)\end{array}$ & $6.13 \pm 0.30$ & $9.84 \pm 0.57^{* * *}$ & $6.91 \pm 0.19$ & $10.53 \pm 0.98^{* * *}$ & $6.85 \pm 0.29$ & $6.38 \pm 0.35$ \\
\hline Atrophy (\%) & $0.10 \pm 0.05$ & $0.29 \pm 0.07^{*}$ & $0.14 \pm 0.03$ & $0.14 \pm 0.03$ & $0.11 \pm 0.04$ & $0.11 \pm 0.03$ \\
\hline
\end{tabular}


Table 3. Percentages of androgen receptor (AR) expression in each cell type in the control, Dextromethorphan only and treatment groups: Control, Dextromethorphan only (DXM), Dextromethorphan+Drug withdrawal (DW60), Dextromethorphan+Diazepam (DD60), Dextromethorphan+GABA standard (DG60) and Dextromethorphan+Pre-germinated brown rice (DP60)

\begin{tabular}{|c|c|c|c|c|c|c|}
\hline Parameter & Control & DXM & DW60 & DD60 & DG60 & DP60 \\
\hline Leydig cell & $60.99 \pm 1.80$ & $29.38 \pm 3.27^{\star * *}$ & $54.83 \pm 1.00^{*}$ & $44.09 \pm 1.92^{* * *}$ & $58.24 \pm 0.70$ & $58.43 \pm 1.21$ \\
\hline Sertoli cell & $58.96 \pm 0.94$ & $32.09 \pm 2.46^{* * * *}$ & $58.77 \pm 0.27$ & $43.61 \pm 1.38^{* * *}$ & $59.42 \pm 0.40$ & $58.37 \pm 0.52$ \\
\hline Spermatogonia & $15.91 \pm 1.09$ & $2.61 \pm 0.51^{* * *}$ & $7.01 \pm 0.41^{\star * *}$ & $5.07 \pm 0.29^{* * *}$ & $10.17 \pm 0.44^{* * *}$ & $13.38 \pm 0.25^{*}$ \\
\hline Round spermatid & $17.45 \pm 0.25$ & $8.07 \pm 0.685^{\star * *}$ & $12.72 \pm 0.15^{* * *}$ & $13.28 \pm 0.46^{* * *}$ & $14.44 \pm 0.42^{* * *}$ & $15.03 \pm 0.27^{* * *}$ \\
\hline Elongated spermatid & $57.24 \pm 0.67$ & $40.08 \pm 0.32^{* \star *}$ & $53.83 \pm 0.95^{*}$ & $52.66 \pm 0.64^{* *}$ & $54.27 \pm 0.99^{*}$ & $54.29 \pm 0.64^{*}$ \\
\hline Peritubular myoid cell & $15.63 \pm 0.25$ & $10.13 \pm 0.07^{* * *}$ & $12.62 \pm 0.61^{* *}$ & $11.41 \pm 0.51^{* * *}$ & $14.76 \pm 0.90$ & $15.07 \pm 0.49$ \\
\hline
\end{tabular}

Values are expressed as mean \pm SEM. Statistical significance is indicated as ${ }^{*} \mathrm{p}<0.05,{ }^{* *} \mathrm{p}<0.01$ and ${ }^{* *} \mathrm{p}<0.001$ in comparison with control group
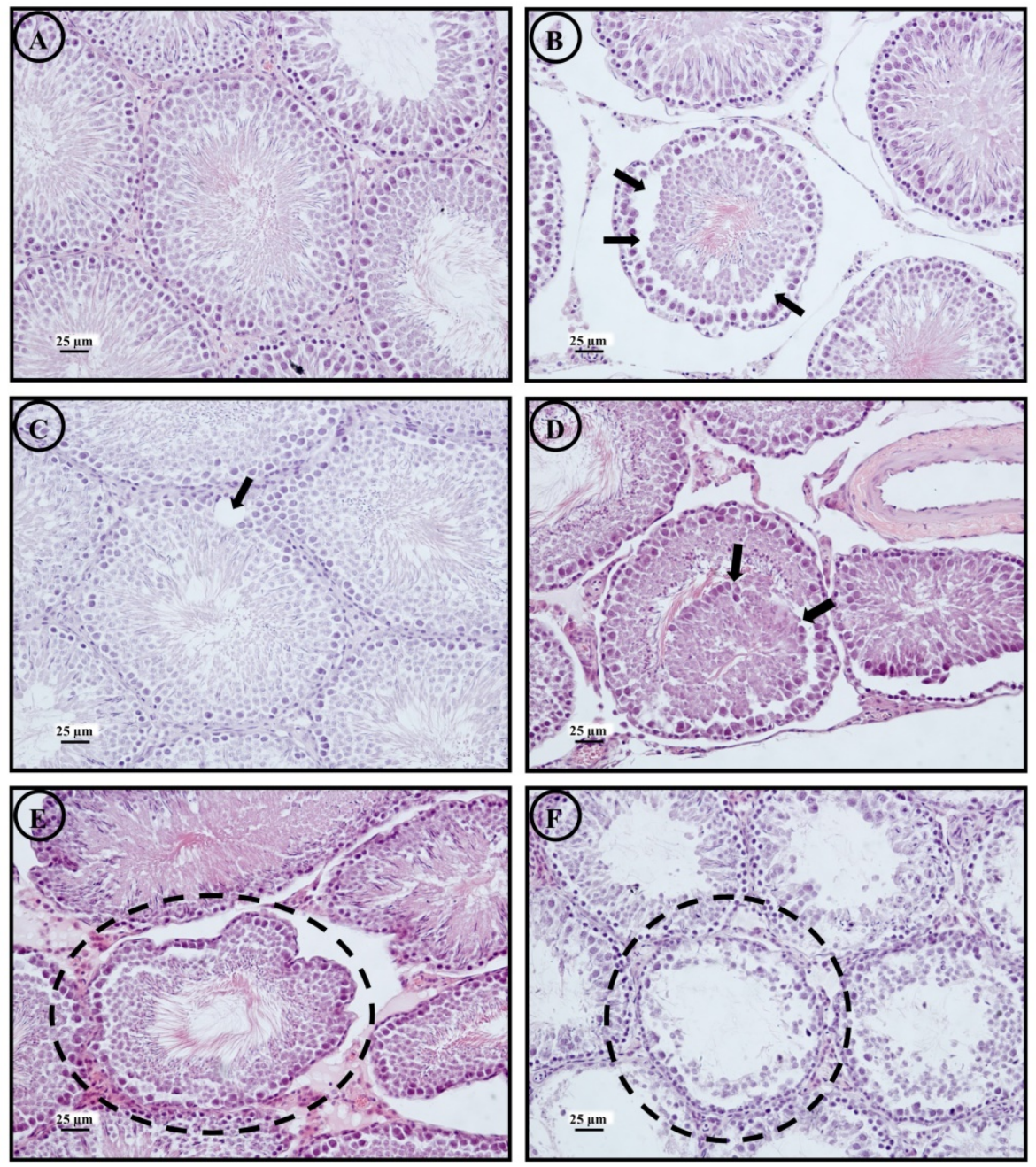

Fig. 2. Morphological changes of seminiferous tubules found in the control and all treatment groups; normal morphology of seminiferous tubule (a), separation of germinal epithelium (arrow) (b), vacuolization of seminiferous tubule (arrow) (c), luminal sloughing of germ cells (arrow) (d), irregular tube of seminiferous tubule (circle) (e) and seminiferous tubule atrophy (circle) (f) (magnification 10X) at scale bar $25 \mu \mathrm{m}$.

\section{Discussion}

\section{Effect of DXM on sperm quality, testicular structure and androgen receptor expression}

The present study demonstrated that DXM has negative effects on sperm quality such as sperm motility, sperm morphology and sperm concentration all of which showed significant decreases when compared with the control group. The results were in agreement with a previous study reporting decreases of sperm motility and normal sperm morphology after DXM [11]. This study reported that DXM can reduce gonadotropin-releasing hormone (GnRH) immunoreactivity in the hypothalamus [11]. The reduction of GnRH may affect the function of anterior pituitary gland to secrete lutinizing hormone (LH) and follicle stimulating hormone (FSH) leading to dysfunction of testosterone production which regulates testicular development and testicular function [12] especially spermatogenesis. Thus, 
reduced sperm quality may be an adverse consequence of the pharmacological action of DXM.

The percentage of testicular weight per body weight (BW) after $30 \mathrm{mg} / \mathrm{kg}$ DXM for 15 days showed a significant increase when compared with the control group. Similarly, morphological changes of seminiferous tubules of these animals showed significant increases in all parameters investigated when compared with the control group. These results may reflect abnormal testicular development due to a reduction of testosterone concentration [13] or the reduction of hormonal receptors in the testis [14] or the changes of sperm-related proteins which are essential for sperm development [15]. Furthermore, the reduction of the peritubular myoid cell contraction results in a congestion of the seminiferous fluid that may cause vacuolization [16], this could relate to the reduction of AR expression in peritubular myoid cells found in the present study. Although the percentage of epididymal weight per body weight was decreased in the DXM-treated group, this could reflect the lack of content inside the epididymal lumen due to a reduction in sperm production and testicular secretions. It has been suggested that exposure to environmental toxicants increases testicular oxidative stress, which leads to an increase in germ cell apoptosis and subsequent hypospermatogenesis [17].

The expression of AR in testicular tissue of rats induced by $30 \mathrm{mg} / \mathrm{kg}$ DXM for 15 days showed a significant decrease of immunopositive cells in all cell

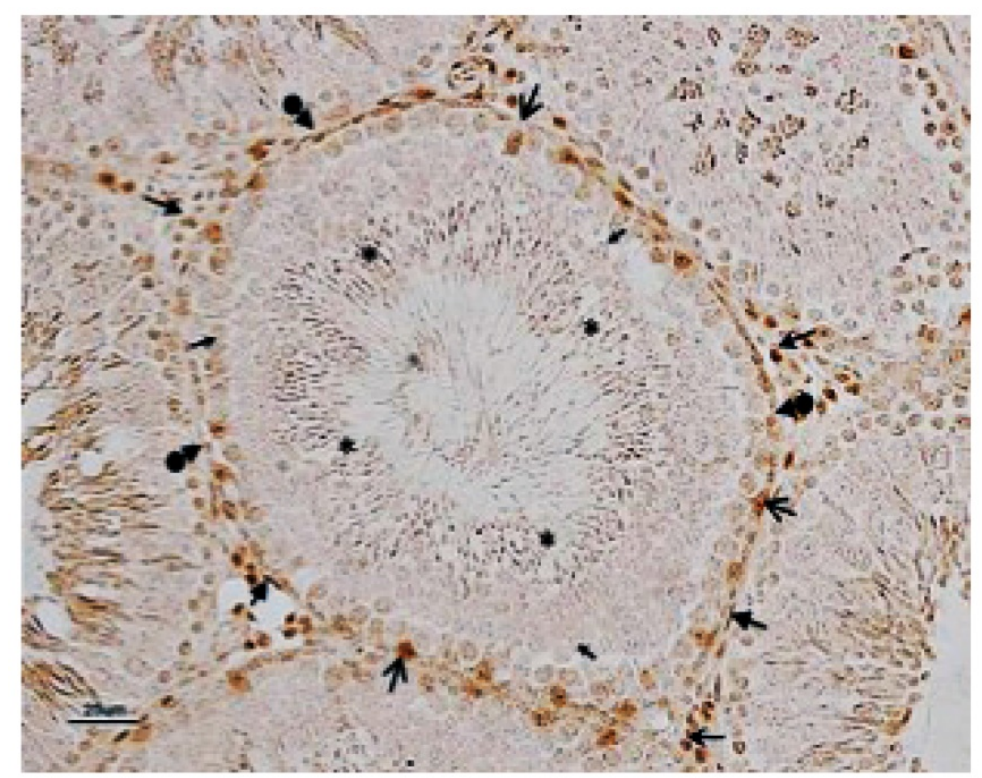

Fig. 3. Seminiferous tubule stained with indirect immunohistochemistry for anti-androgen receptor technique. Androgen receptor positive cell are located in nuclei of Leydig cell ( $\uparrow$ ), Sertoli cell ( $\boldsymbol{\uparrow}$ ), spermatogonia $(\boldsymbol{\uparrow})$, round spermatid $(\boldsymbol{\boldsymbol { \phi }})$, elongated spermatid $(*)$, and peritubular myoid cell ( $\boldsymbol{(}$ ) (magnification 10X) at scale bar $25 \mu \mathrm{m}$. types when compared with the control group. The reduction of immunopositive Leydig cells may be due to the reduction of $\mathrm{GnRH}$ in the hypothalamus [11] which may also decrease AR expression in Leydig cells. The reduction of AR expression in these cells therefore induces the decrease of androgen secretion which may affect AR expression in Sertoli cells and other target cells of androgen action. The reduction of AR in Sertoli cells has been reported to affect the development of spermatogonia and the spermatogenic phenotype [18]. Additionally, AR function in Sertoli cells is to regulate spermatid adhesion to the seminiferous epithelium [18]. Consequently, the reduction of AR in Sertoli cells may influence sperm development as well as spermiation.

\section{Recovery effect of drug withdrawal on sperm quality, testicular structure and androgen receptor expression in rat model of addiction}

In the present study, the sperm motility of DW60 showed no statistically significant difference when compared with the control group while sperm morphology and sperm concentration showed significant decreases. It has been reported that DXM is rapidly absorbed within 30 minutes in the gastrointestinal tract. The duration of DXM is about 3-6 hours and half-life of about 2-4 hours [19], while the entire process of spermatogenesis takes approximately 21 days in rat. Therefore, sperm motility may recover after some period of withdrawal but sperm morphology and sperm concentration may demonstrate enduring damage following the period of DXM treatment.

In addition, DW60 showed a significant decrease of immunopositive cells in Leydig cells, spermatogonia, round spermatid, elongate spermatid and peritubular myoid cells when compared with the control group. These results may reflect a reduction of testosterone concentration leading to abnormalities of sperm morphology and sperm concentration.

\section{Recovery effect of diazepam on sperm quality, testicular structure and androgen receptor expression in rat model of addiction}

All parameters of sperm quality in DD60 showed significant decreases when compared with control group. These could reflect the fact that diazepam acts as an aneugen in spermatogenesis, which may cause daughter cell aneuploidy [20].

The morphological changes of seminiferous tubules in DD60 showed significant 
increases in the percentages of vacuolization and irregular tubule when compared with the control group. These morphological changes of seminiferous tubules may relate to decreased testosterone concentration caused by DXM [13]. Reduction of testosterone concentration affects degeneration of Sertoli cell-Sertoli cell junctions that involve in morphological changes of seminiferous tubules. In addition, reduction of testosterone concentration induced the degeneration of the peritubular myoid cell contraction resulting in congestion of the seminiferous fluid may cause vacuolization [16], that related with reduction of AR expression in peritubular myoid cell. It is possible that diazepam has not only shown its recovery effect on the morphological changes of seminiferous tubules resulted from DXM. but also may have an adverse effect on structure of seminiferous tubule which may lead to spermatogenesis deficiency.

\section{Recovery effect of GABA on sperm quality, testicular structure and androgen receptor expression in rat model of addiction}

In terms of sperm quality, DG60 showed no statistically significant difference from controls only in sperm concentration. This could reflect a recovery effect of GABA on the number of sperm production but not in sperm morphology and sperm motility. A previous study showed that GABA can modulate GnRH secretion [21] which, as mentioned, has an important role in regulation of $\mathrm{FSH}, \mathrm{LH}$ and testosterone levels, the essential hormones for spermatogenesis. Moreover, the expression of GABA receptors on germ cells has been reported [22, 23, 24] and which may be directly involved in the regulation of sperm quality.

The percentage of testicular weight per body weight (BW) and the morphological changes of seminiferous tubules in DG60 showed showed no statistically significant differences when compared with control group. Jackson and Kuehl (2002) [21] reported can GABA modulate $\mathrm{GnRH}$ secretion. Therefore, GABA treatment for 60 days shows its recovery effect on testicular structure after DXM administration. These may due to the recovery of AR expression in Sertoli, Leydig and peritubular myoid cells which may be involved in testicular structure development.

\section{Recovery effect of PGBR on sperm quality, testicular structure and androgen receptor expression in rat model of addiction}

In the present study, all parameters of sperm quality, the percentage of testicular weight per body weight (BW) and the morphological changes of seminiferous tubules measured in DP60 showed no significant differences when compared with the control group. These could reflect a recovery effect of PGBR treatment in rats administered DXM. It has been reported that PGBR has GABA in high amounts, which can help in the regulation of sperm quality [10, 22, 23, 24, 25, 26]. In addition, PGBR contains abundant antioxidants including $\gamma$-oryzanol, a-tocopherol, pyridoxine and thiamine. Previous studies showed that antioxidants can enhance sperm quality, especially $\gamma$-oryzanol and a-tocopherol [27, $28,29]$. $\gamma$-Oryzanol has been reported to improve the sperm morphology from lipid peroxidation [28]. In addition, supplementation of $\gamma$-oryzanol can increase sperm concentration and sperm motility. Furthermore, a-tocopherol in combination with a-tocopherol effectively improved semen quality [30]. This may well contribute to the fact that prolonged treatment with PGBR can recover sperm quality and testicular structure development in this animal model of drug addiction.

The expression of AR in DP60 showed significant decreases only in spermatogenic cells. This could reflect sensitivity of these cells to DXM. However, prolonged treatment with PGBR may recover AR expression in these spermatogenic cells as they may take longer to recover than Sertoli, Leydig and peritubular myoid cells.

\section{Conclusions}

The present study showed that PGBR treatment can enhance recovery of sperm quality, of morphological changes of seminiferous tubules and of AR expression in DXM-treated animals. These results suggested that PGBR, containing high amounts of GABA and antioxidants, may enhance the function of $\mathrm{GnRH}$ and related hormones in the regulation of testicular development, testicular function and spermatogenesis. In addition, prolonged PGBR administration showed no adverse effect on sperm quality, morphological changes of seminiferous tubules and AR expression. Therefore, PGBR may be a novel therapeutic strategy for the consequences of drug addiction in the future.

\section{Acknowledgements}

We would like to send our sincere thanks to Assoc. Prof. Dr. Sudarat Jiamyangyuen, Faculty of Agriculture, NU for providing us the PGBR, NU hospital for providing us with diazepam and Faculty of Medical Science, NU for all laboratory facilities. This study was financially supported by Agricultural Research Development Agency (ARDA) Thailand and NU Research Fund. 


\section{Author contributions}

$S$ Thanoi and S Nudmamud-Thanoi performed the experimental designs. J Roboon, S NumamudThanoi and S Thanoi performed the experiments. S Thanoi wrote the manuscript with all authors having read and approved the final manuscript.

\section{Competing Interests}

The authors have declared that no competing interest exists.

\section{References}

1. Schenker JG, Meirow D, Schenker E. Stress and human reproduction. Eur J Obstet Gynecol Reprod Biol. 1992; 45: 1-8.

2. Nakashima A, Koshiyama K, Uozumi T, Monden Y, Hamanaka Y, Kurachi K. Effects of general anaesthesia and severity of surgical stress on serum LH and testosterone in males. Acta Endocrinol. 1975; 78: 258-269.

3. Yesavage JA, Davidson J, Widrow L, Berger P. Plasma testosterone levels, depression, sexuality, and age. Biol Psychiatry. 1985; 20: 199-228.

4. Schneider-Kofman N, Sheiner E. Does stress effect male infertility? -A debate. Med Sci Monit. 2005; 11: SR11-13.

5. Collodel G, Moretti E, Fontani V, Rinaldi S, Aravagli L, Sarago G. Effect of emotional stress on sperm quality. Indian J Med Res. 2008; 128: 254-261.

6. Nudmamud-Thanoi S, Thanoi S. Methamphetamine induces abnormal sperm morphology, low sperm concentration and apoptosis in the testis of male rats. Andrologia. 2011; 43: 278-282.

7. Nudmamud-Thanoi S, Thanoi S. Pseudoephedrine induces sperm abnormalities, lower sperm counts and increased apoptosis in rat testis. Cell Tissue Res. 2012; 349: 625-630

8. Yamamoto $\mathrm{Y}$, Yamamoto $\mathrm{K}$, Hayase $\mathrm{T}$, Abiru $\mathrm{H}$, Shiota $\mathrm{K}$, Mori $\mathrm{C}$. Methamphetamine induces apoptosis in seminiferous tubules in male mice testis. Toxicol Appl Pharmacol. 2002; 178: 155-60.

9. Schwartz AR, Pizon AF, Brooks DE. Dextromethorphan-induced serotonin syndrome. Clin Toxicol. 2008; 46: 771-773.

10. Roboon J, Nudmamud-Thanoi S, Thanoi S. Recovery effect of pre-germinated brown rice on the alteration of sperm quality, testicular structure and androgen receptor expression in rat model of depression. Andrologia. 2017; 49: doi: 10.1111/and.12596.

11. Nam Y, Shin EJ, Yang BK, Bach JH, Jeong JH, Chung YH, Park ES, Li Z, Kim KW, Kwon YB, Nabeshima T, Kim HC. Dextromethorphan-induced psychotoxic behaviors cause sexual dysfunction in male mice via stimulation of o-1 receptors. Neurochem Int. 2012; 61: 913-922.

12. Sharpe RM. Regulation of spermatogenesis. The Physiology of Reproduction. Raven Press, New York, 1994; 1363-1434.

13. Russell LD, Malone JP, Karpas SL. Morphological patterns elicited by agents affecting spermatogenesis by disruption of its hormonal stimulation. Tissue cell. 1981; 13: 369-380.

14. Nudmamud-Thanoi S, Sueudom W, Tangsrisakda N, Thanoi S. Changes of sperm quality and hormone receptors in the rat testis after exposure to methamphetamine. Drug Chem Toxicol. 2016; 39:432-438.

15. Ashrafzadeh A, Karsani SA, Nathan S. Mammalian sperm fertility related proteins. Int J Med Sci. 2013; 10: 1649-57.

16. Creasy DM. Pathogenesis of male reproductive toxicity. Toxicol Pathol. 2001; 29: 64-76.

17. Turner TT, Lysiak JJ. Oxidative stress: a common factor in testicular dysfunction. J Androl. 2008; 29: 488-498.

18. Holdcraft RW, Braun RE. Androgen receptor function is required in Sertoli cell for the terminal differentiation of haploid spermatids. Development. 2003; 131: $459-467$

19. Shaul WL, Wandell M, Robertson WO. Dextromethorphan toxicity: Reversal by naloxone. Pediatrics. 1997; 59: 117-118.

20. Baumgartner A, Schmid TE, Schuetz CG, Adler ID. Detection of aneuploidy in rodent and human sperm by multicolor FISH after chronic exposure to diazepam. Mutat Res. 2001; 490: 11-19.

21. Jackson GL, Kuehl D. Gamma-amonobutyric acid (GABA) regulation of GnRH secretion in sheep. Reproductive (Suppl). 2002; 59: 15-24.

22. $\mathrm{He} \mathrm{XB}, \mathrm{Hu} \mathrm{JH}, \mathrm{Wu} \mathrm{Q}, \mathrm{Yan} \mathrm{YC}$, Koide SS. Identification of $\mathrm{GABA}_{\mathrm{B}}$ receptor in rat testis and sperm. Biochem Biophys Res Commun. 2001; 283: 243-247.

23. $\mathrm{Hu} \mathrm{JH}, \mathrm{He} \mathrm{XB}, \mathrm{Wu} \mathrm{Q}, \mathrm{Yan} \mathrm{YC}$, Koide SS. Subunit composition and function of GABAA reseptors of rat spermatozoa. Neurochem Res. 2002; 27: 195-199.

24. Li S, Zhang Y, Liu H, Yan Y, Li Y. Identification and expression of GABAc receptor in rat testis and spermatozoa. Acta Biochim Biophys Sin (Shanghai). 2008; 40: 761-767.

25. Calogero AE, Hall J, Fishel S, Green S, Hunter A, D'Agata R. Effects of $\mathrm{\gamma}$-aminobutyric acid on human sperm motility and hyperactivation. Mol Hum Reprod. 1996; 2: 733-738.
26. Kanbara K, Okamoto $\mathrm{K}$, Nomura S, Kaneko T, Shigemoto R, Azuma H. Cellular localization of GABA and GABAB receptor subunit proteins during spermiogenesis in rat testis. J Androl. 2005; 26: 485-493.

27. Greco E, Iacobelli M, Rienzi L, Ubaldi F, Ferrero S, Tesarik J. Reduction of the incidence of sperm DNA fragmentation by oral antioxidant treatment. J Androl. 2005; 26: 349-353.

28. Arlas TR, Pederzolli CD, Terraciano PB, Trein CR, Bustamante-Filho IC, Castro FS. Sperm quality is improved feeding stallions with a rice oil supplement. Anim Reprod Sci. 2008; 107: 306.

29. Lanzafame F. Oxidative stress and medical antioxidant treatment in male infertility. Reprod Biomed Online. 2009; 19: 638-659.

30. Marin-Guzman J, Mahan DC, Chung YK, Pate JL, Pope WF. Effects of dietary selenium and Vitamin $\mathrm{E}$ on boar performance and tissue responses, semen quality, and subsequent fertilization rates in mature gilts. J Anim Sci. 1997; 75: 2994-3003. 